Vol 11, Issue 8, 2018

\title{
KNOWLEDGE, ATTITUDE, AND BEHAVIORS TOWARD ANTIBIOTICS OF NON-MEDICAL STUDENTS JOUF UNIVERSITY, SAUDI ARABIA
}

\author{
GOMAA MOSTAFA-HEDEAB ${ }^{1,2 *}$ \\ ${ }^{1}$ Department of Pharmacology, Medical College, Jouf University, Saudi Arabia. ${ }^{2}$ Department of Pharmacology, Faculty of Medicine, Beni-Suef \\ University, Egypt. Email: Gomaa_hedeab@yahoo.com
}

Received: 28 March 2018, Revised and Accepted: 03 May 2018

\section{ABSTRACT}

Objective: The objective of the study was to investigate the knowledge and attitude of non-medical students, Jouf University toward antibiotic.

Methods: Data were collected from male and female students using a self-prepared questionnaire then tabulated and analyzed using SPSS program.

Results: This study included 1035 students; 573 (55.3\%) male and 462 (44.6\%) female, aged (21.5 \pm 2.2$)$ years. About 533 (51.5\%) used antibiotic during the year 2015. 705 (68.12\%) of the student display wrong answer regarding the uses of the antibiotic. 53.5\% depending on the previous prescription on self-medicated antibiotic (SAM), followed by their experience (14.5\%) and pharmacy advice (11.3\%). 45.9\% did not have any idea about the antibiotic name they used. Majority of the students (62.6\%) stop antibiotic once improvement is achieved, whereas (28.1\%) complete the course till the end of the last dose. $75.4 \%$ of the studied populations saving at least one antibiotic at home while $62.7 \%$ sharing antibiotic with others. $35.3 \%$ of the studied population did not experienced antibiotic-related side effects, while $19.3 \%$ experience nausea. About $57.6 \%$ believed that broad spectrum is better than narrow-spectrum antibiotic, $70.4 \%$ deny that higher doses enhance recovery, (57.3\%) believes that low dose decrease side effect. $51.9 \%$ depend on their good medical knowledge for SMA, while $20.3 \%$ was to save time, $18.8 \%$ dependent on pharmacy expert where only $9 \%$ was to save money cost.

Conclusion: The majority of the sample had a fair level of knowledge in relation to antibiotics. Initiation of national program and campaigns toward antibiotic uses to raise the public awareness about the hazardous of antibiotic misuse/abuse is essential to decrease the gap between antibiotic use and attitude.

Keywords: Antibiotic, Attitude, Behavior, Non-medical student, Jouf University.

(c) 2018 The Authors. Published by Innovare Academic Sciences Pvt Ltd. This is an open access article under the CC BY license (http://creativecommons. org/licenses/by/4. 0/) DOI: http://dx.doi.org/10.22159/ajpcr.2018.v11i8.26308

\section{INTRODUCTION}

It has been estimated worldwide that more than $50 \%$ of the antibiotics are sold without a medical prescription [1]. Antibiotic misuse increases the risk of appearing resistant bacteria which make the antibiotic prescription choices so difficult by physicians [2]. This phenomenon is not limited to the developing countries, but it is also reported in many European countries as Spain, Greece, Portugal as well as Mexico, and Brazil [3-7] indicating the worldwide spread of this problem. The dispensing without a prescription is a serious problem in most of the Arab countries as Egypt, Syria, Jordan, as well as Saudi Arabia [8-10].

Previous studies conducted in Saudi Arabia showed that antibiotic dispense is reported by $78 \%$ of surveyed community pharmacies in Riyadh and 98\% community pharmacies in Jeddah [11]. This antibiotic dispense not only without prescription but also without an evidencebased indication [12].

Few studies are dealing with population attitudes toward misuse of antibiotics, up to our knowledge no study was done among non-medical student, Jouf University.

\section{METHODS}

This was a questionnaire-based descriptive cross-sectional study conducted among non-medical students, Jouf University, Kingdom of Saudi Arabia. This study was conducted in College of Humanities and Administrative Sciences, Community College, College of Engineering, College of Education, College of Law, College of Science, and College of Science and Arts. Data collection questionnaire of the present study was conducted in Arabic language and translated later into English.
Inclusion and exclusion criteria

Male and female students enrolled in undergraduate or postgraduate programs of all academic years were invited for participation in this study. Participation was voluntary and without any compensation. Medical, pharmacy and paramedical students were excluded from the study.

\section{Data collection procedure}

Students were approached during teaching hours at classrooms of different colleges, Jouf University. The self-administered questionnaire filling was considered as informed consent from a student who agrees to participate. After filling the questionnaire by the students, it returned back for data collections and manipulation.

\section{Ethical consideration}

The study was approved by the Ethical Committee, College of Medicine, Jouf University. Returning the completed survey was accepted as the consent of participation by the participating students.

\section{Statistical analysis}

Data collected, tabulated and subjected to analysis using SPSS version 19 Chi-square test was used for descriptive data.

\section{RESULTS}

Demoic data for students included in the study are presented in Table 1; showed that 1035 students enrolled in the study aged $21.5 \pm 2.2$; there were $573(55.3 \%)$ male students, 462 (44.6\%) female students. $75 \%$ of the total student having monthly income more than 5000 Saudi Riyal. 533 (51.5\%) had a strong concept that they used antibiotic during 2015. 


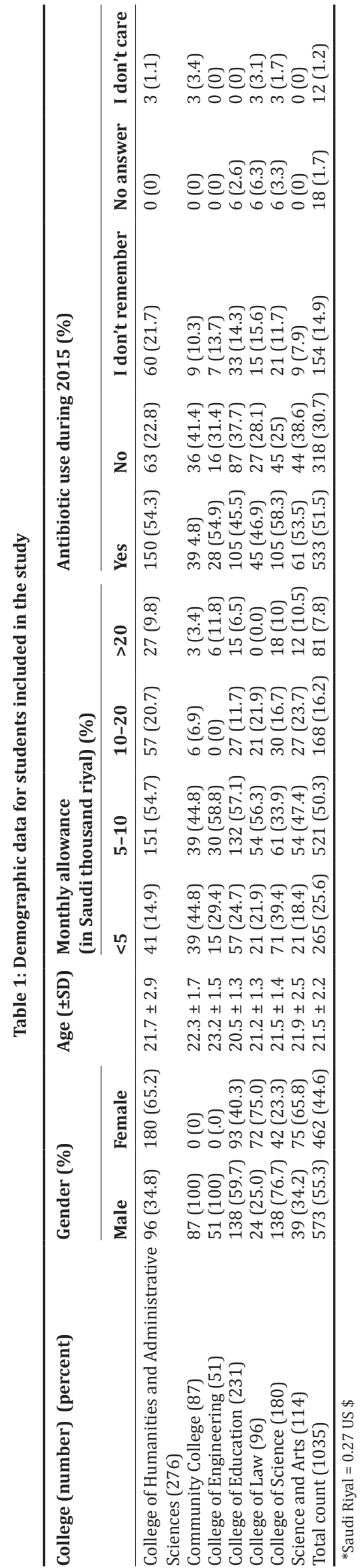

Among the students enrolled in the study; 705 (68.12\%) of the student display wrong answer regarding the uses of the antibiotic, while the right answer was obtained from 225 (21.73\%); Furthermore, 105 students $(10.14 \%)$ did not know the reason for antibiotic intake (Table 2).

The bases of the antibiotic selection among non-medical students Jouf University were examined; $53.5 \%$ of students depend on the previous prescription, followed by their experience $(14.5 \%)$ whereas pharmacy advice represents the third choice (11.3\%) (Table 3).

Among antibiotics list included for the participants to choose their previously used one; $45.9 \%$ of the students included in the study did not have any idea about the antibiotic name they used, where amoxicillin, ampicillin, and augmentin were selected by $14.2 \%, 13.1 \%$, and $11.4 \%$ of population sample, respectively (Table 4). Majority of the students $(62.6 \%)$ stop antibiotic once improvement is achieved, whereas (28.1\%) complete the course till the end of the last dose (Table 5).

In the present study, $75.4 \%$ of the studied populations saving at least one antibiotic at home for upcoming uses if needed while (62.7\%) sharing antibiotic with others (Table 6).

About (35.3\%) not experienced side effects, while 19.3\% experience nausea as side effect, whereas $18.6 \%$ believed that they experience drug resistance which is displayed by ineffectiveness of the antibiotic used, followed by vomiting $(9.5 \%)$, skin rash $(9.5 \%)$, and diarrhea (7.8\%) (Table 7).

Some concepts and attitude toward antibiotic uses were examined; about $(57.6 \%)$ believed that broad is better than narrow-spectrum antibiotic, (70.4\%) deny that higher doses enhance recovery, and (57.3\%) believes that low dose decrease side with insignificant differences between male and female $(p=0.658,0.538,0.613$, and 0.9$)$, respectively (Table 8).

The reason for which students included the study self-medicated antibiotic (SAM) are variables where $51.9 \%$ depend on their good medical knowledge, $20.3 \%$ was to save time, $18.8 \%$ depending on the advice of expert pharmacy where only $9 \%$ was to save money and decrease the cost (Table 9).

\section{DISCUSSION}

The SMA is a serious medical problem still receiving updates [13-15]. SMA rates have been reported as $24-90 \%$ in university students from different regions and countries [16-19]. SMA percent in the developing countries is much higher compared to the developed ones [20]. Our present study focused in particular on the non-medical students, Jouf University, KSA.

The prevalence of SMA may reach burden percent; it is up to $47.8 \%$ in Southern China, $79.5 \%$ in Sudan, and 48\% in Iran $[16,19,21]$.

In the present study, the majority (68.12\%) of the student enrolled in the present study display the wrong answer regarding the uses of the antibiotic; right answer was obtained from $21.73 \%$ of the studied population.

The results demonstrated the prevalence of misunderstandings about antibiotic use that may result in unnecessary risk of antibiotic-resistant infection. It may increase the health-care system cost and antibioticrelated side effect; the relationship between patient knowledge and antibiotics use attitude is highly linked [20,22-25]

Our result differs from the previous study on medical Saudi students showed only $18.1 \%$ of the responders believe that antibiotic is antiviral [26]. This difference is expected due to medical knowledge and background of differences between students in both groups. 
Shehadeh et al. [27] showed $67.1 \%$ of Jordanian population included in the study believed that antibiotics treat common cold and cough, while Zhu et al. [28] in another study showed that $43.5 \%$ believed that antibiotic was sui for viral infections.

Our results are less than results of Oh et al. [29] and Lim et al. [30] who showed $86.6 \%$ and $83 \%$ of the population included in their study belief that antibiotic is used into treat viral infections, respectively. McNulty et al., ${ }^{[31]}$ showed that $53 \%$ of the population included in his study believed that the antibiotic act as antiviral.

The present results could be explained by the inadequacy of knowledge in this area that may be due to using the term "germ," which was normally used during medical counseling rather than the microbiological terms "bacteria" or "virus" [29].

In the present results, $53.5 \%$ of students depend on the previous prescription for SMA, followed by their experience (14.5\%) whereas pharmacy advice representing the third choice (11.3\%).

This present result is an alarming notice for a society lacking appropriate public medical education. More restriction for SMA should be applied.

Zhu et al. [28] showed $64.8 \%$ depend on the own their experience for SMA while $31.1 \%$ due to community pharmacist advice. Among Jordanian population, $51.8 \%$ of the studied population, using antibiotics based on relative advice [27].

Among antibiotics list included for the participants to choose their previously used one; (45.9\%) of the students included in the study did not have any idea about the antibiotic name, where amoxicillin, ampicillin, and augmentin were selected by $14.2 \%, 13.1 \%$, and $11.4 \%$, respectively.

These results could be explained as the patients are not getting enough information from health-care professionals concerning the drugs they use.

Majority of the students (62.6\%) stop antibiotic once improvement is achieved, whereas $(28.1 \%)$ complete the course till the end of the last dose.

A similar result was published by Rao et al. [32] showed $65.55 \%$ of the population included will stop taking a full course of antibiotics if their symptoms are improved.
Our results are higher than a study done by Mouhieddine et al. [33] on Lebanese population who showed that only $38.6 \%$ stop antibiotic once improving symptoms are achieved.

This high percentage of people who stop their antibiotic course once improvement is achieved may be a major contributor to the rapid increase in resistant bacterial infections. The misconception carries the risk of infection relapse, bacterial colonization, and complicated disease outcomes [34,35].

The incompletion of the antibiotic course will lead to antibiotic subinhibitory concentrations inside the body that will result in the development of resistant pathogen [36].

In the present study, $75.4 \%$ of the studied populations saving at least one antibiotic at home for upcoming uses if needed. Among all non-medical student enrolled in the present study, (62.7\%) sharing antibiotic with others.

Mouhieddine et al. [33] showed in Lebanese population 52.1\% usually keep antibiotic stocks at home and $26.5 \%$ usually give our antibiotics to a sick family member, Lim et al. [30] showed that 17\% keep antibiotic stock at home for the emergency purpose. Oh et al. showed nearly the same percent (19.9\%) [29]

In tertiary-care, keeping antibiotic stocks at home in case of emergency are believed by $48.33 \%$ of the population, while sharing antibiotics with a family member if they are sick are accepted by only $31.11 \%$ [32]. Shehadeh [27], in Jordanian population survey, showed 28.5\% kept antibiotics at home for emergency use.

In the current work, $35.3 \%$ of the studied population not experienced antibiotic-related side effects, while nausea is the first most common experiencing side effect (19.3\%), whereas $18.6 \%$ (believed that they experience drug resistance which is displayed by ineffectiveness of the antibiotic used, followed by vomiting ( $9.5 \%)$, skin rash (9.5\%), and diarrhea (7.8\%).

In previous study Lim et al. [30] showed that $52 \%$ did not experience antibiotic-associated side effects.

In the present study, $57.6 \%$ believed that broad-spectrum antibiotic is better than narrow-spectrum (70.4\%) deny that higher doses enhance recovery, $57.3 \%$ believed that low dose decrease side effects while

Table 2: Concepts of the antibiotic uses among students included in the study

\begin{tabular}{|c|c|c|c|c|}
\hline Answer* & $\begin{array}{l}\text { Correct } \\
\text { answer (antimicrobial) (\%) }\end{array}$ & Wrong answer (\%) & & $\begin{array}{l}\text { I do not } \\
\text { know }(\%)\end{array}$ \\
\hline Number of students (1035) & $225(21.73)$ & $\begin{array}{l}705(68.12) \\
\text { Analgesic } 537 \text { (76.17) } \quad \text { Antipyretic } 75 \text { (10.64) }\end{array}$ & Colic 93 (13.19) & $105(10.14)$ \\
\hline
\end{tabular}

*Sig. distribution differences

Table 3: Bases of the anti-biotic selection among non-medical students Jouf University

\begin{tabular}{llllll}
\hline Gender & Previous prescription (\%) & Nurse a devise (\%) & Pharmacy a device (\%) & Own experience (\%) & Relatives (\%) \\
\hline Total (\%) & $554(53.5)$ & $115(11.1)$ & $117(11.3)$ & $150(14.5)$ & $99(9.6)$ \\
Male & $338(59)$ & $61(10.6)$ & $45(7.9)$ & $72(12.6)$ & $57(9.9)$ \\
Female & $216(46.8)$ & $54(11.7)$ & $72(15.6)$ & $78(16.9)$ & $42(9.1)$ \\
\hline
\end{tabular}

Table 4: Types of antibiotic commonly used among non-medical students Jouf University

\begin{tabular}{llllll}
\hline Gender & Ampicillin (\%) & Amoxicillin (\%) & Augmentin (\%) & Other (\%) & I do not know (\%) \\
\hline Total (\%) & $136(13.1)$ & $147(14.2)$ & $118(11.4)$ & $159(15.4)$ & $475(45.9)$ \\
Male & $70(12.2)$ & $84(14.7)$ & $40(7)$ & $93(16.2)$ & $286(49.9)$ \\
Female & $66(14.3 \%$ & $63(13.6)$ & $78(16.9)$ & $66(14.3)$ & $189(40.9)$ \\
\hline
\end{tabular}


$57 \%$ believed that switching antibiotic enhance drugs effects. The prevalence of inappropriate attitudes was higher compared to previous work [29,31,37].

In the present work, the reason for which students included the study SAM are variables; where $51.9 \%$ depend on their good medical knowledge, while $20.3 \%$ was to save time, whereas who depend on pharmacy expert was $18.8 \%$ where only $9 \%$ was to save money and decrease the cost.

In Saudi community, all populations are covered by health insurance; this explained why the cost factor is the last one for SMA.

Antibiotic carry several risks, especially when used without a physician prescription. The exact burden of this problem is not known [38].

Many recommendations should be applied to raise the awareness toward self-medication; drugs that are available without the need for prescription by a physician or trained medical personnel should only be the ones which are safe to use. The government should also ensure that users are educated properly about not only the use of

Table 5: Complete drug used

\begin{tabular}{llll}
\hline Gender & $\begin{array}{l}\text { End of the } \\
\text { dose (\%) }\end{array}$ & Improvement (\%) & $\begin{array}{l}\text { Change every } \\
\text { time (\%) }\end{array}$ \\
\hline Number (\%) & $291(28.1)$ & $648(62.6)$ & $96(9.3)$ \\
Male & $132(23.0)$ & $363(63.4)$ & $78(13.6)$ \\
Female & $159(34.4)$ & $285(61.7)$ & $18(3.9 \%)$ \\
\hline
\end{tabular}

the drug but also the correct dosages, duration of use and potential side effects associated with them as antibiotics are tailored not only according to the disease but also according to the individual patient profile.

Effective doctor-patient communication and patient empowerment have been shown to reduce antibiotic prescribing for coughs and colds in the primary care setting [39]. Besides the knowledge, instilling the right attitude should also be a priority as simply increasing public knowledge on antibiotics has been shown to cause higher incidences of self-medication [31].

Unfortunately, the damage caused by the misuse of antibiotics goes beyond the damage caused by the drug itself. The damage includes killing the beneficial bacteria in our body (e.g., in the gastrointestinal tract), disruption of the immune system's normal functioning, and many other side effects.

The WHO has become concerned about the rising levels of resistant bacteria around the world. To provide global coordination, the WHO issued its Global Strategy for Containment of Antimicrobial Resistance, a document aimed at policy-makers that urge governments to take action.

South Korea created the National Antimicrobial Resistance Experts Committee in 2003, which, in turn, has implemented a number of national educational campaigns on the appropriate use of antibiotics in various ways targeted to the general public [40]. The results of this study show that the need to implement a similar campaign or else face the consequences associated with the misuse of antibiotics.

Table 6: Saving antibiotic at home for use

\begin{tabular}{|c|c|c|c|c|c|c|c|c|c|}
\hline \multirow[t]{2}{*}{ Gender } & \multicolumn{2}{|c|}{$\begin{array}{l}\text { Saving antibiotic at } \\
\text { home }(\%)\end{array}$} & \multicolumn{4}{|c|}{ Incomplete drug course $(\%)$} & \multicolumn{3}{|c|}{ Share antibiotic with others (\%) } \\
\hline & Yes & No & Improvement & Side effect & Bad taste & Ineffective & Yes always & Never & Occasionally \\
\hline Count (\%) & $780(75.4)$ & 255 (24.6) & $546(52.8)$ & 165 (15.9) & 309 (29.9) & $15(1.4)$ & $649(62.7)$ & $298(28.8)$ & $88(8.5)$ \\
\hline Male & $450(78.5)$ & $123(21.5)$ & $330(57.6)$ & $78(13.6)$ & 153 (26.7) & $12(2.1)$ & 304 (53.1) & $202(35.3)$ & 67 (11.7) \\
\hline Female & $330(71.4)$ & 132 (28.6) & $216(46.8)$ & 87 (18.8) & 156 (33.8) & $3(0.6)$ & 345 (74.7) & $96(20.8)$ & $21(4.5)$ \\
\hline
\end{tabular}

Table 7: Experience side effects

\begin{tabular}{|c|c|c|c|c|c|c|}
\hline Gender & Nausea (\%) & Vomiting (\%) & Diarrhea (\%) & Skin rash (\%) & Drug resistance $(\%)$ & No side effects $(\%)$ \\
\hline Total (\%) & 200 (19.3) & $98(9.5)$ & $81(7.8)$ & $99(9.5)$ & $192(18.6)$ & $365(35.3)$ \\
\hline Male & $110(19.2)$ & $58(10.1)$ & $51(8.9)$ & 75 (13.1) & $105(18.3)$ & $174(30.4)$ \\
\hline Female & $90(19.5)$ & $40(8.7)$ & $30(6.5)$ & $24(5.2)$ & $87(18.8)$ & $191(41.3)$ \\
\hline
\end{tabular}

Table 8: Some concepts and attitude toward antibiotic uses

\begin{tabular}{|c|c|c|c|c|c|c|c|c|}
\hline \multirow[t]{2}{*}{ Gender } & \multicolumn{2}{|c|}{$\begin{array}{l}\text { Broad is better than } \\
\text { narrow }^{\# \#}(\%)\end{array}$} & \multicolumn{2}{|c|}{$\begin{array}{l}\text { Higher doses enhance } \\
\text { recovery }^{\# \#}(\%)\end{array}$} & \multicolumn{2}{|c|}{ 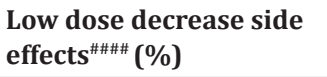 } & \multicolumn{2}{|c|}{ 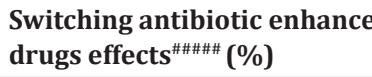 } \\
\hline & Yes & No & Yes & No & Yes & No & Yes & No \\
\hline Total (\%) & $596(57.6)$ & $439(42.4)$ & 306 (29.6) & $729(70.4)$ & $593(57.3)$ & $442(42.7)$ & \# 445 (43.0) & $590(57.0)$ \\
\hline Male & 326 (56.9) & 247 (43.1) & $174(30.4)$ & 399 (69.6) & $324(56.5)$ & 249 (43.5) & $245(42.8)$ & $328(57.2)$ \\
\hline Female & $270(58.4)$ & $192(41.6)$ & 132 (28.6) & $330(71.4)$ & 269 (58.2) & 193 (41.8) & $200(43.3)$ & 262 (56.7) \\
\hline
\end{tabular}

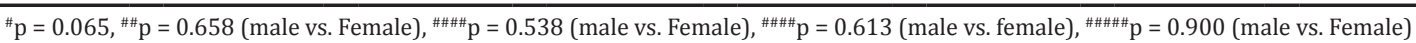

Table 9: Cause of self-medication

\begin{tabular}{|c|c|c|c|c|}
\hline \multirow[t]{2}{*}{ Gender } & \multicolumn{4}{|l|}{ Cause of self-medication } \\
\hline & Good medical knowledge & The decrease of the cost & No time available & Pharmacy expert \\
\hline Total (\%) & 537 (51.9) & $93(9.0)$ & $210(20.3)$ & $195(18.8)$ \\
\hline Male & 333 (58.1) & $33(5.8)$ & $96(16.8)$ & $111(19.4)$ \\
\hline Female & $204(44.2)$ & $60(13.0)$ & $114(24.7)$ & $84(18.2)$ \\
\hline
\end{tabular}


Interventions are usually aimed at specific populations and risk factors [41]; however, reported SMA risk factors are varied and inconsistent across the studies $[16,17,19,42,43]$. One of the most important and effective way to decrease the incidence and hazardous of SMA is initiating an educational program for the public and antibiotic sales/use restriction by law and regulation implementation [41]. An interesting example for this is Chile interventions which included strict restriction on over-the-counter sales of antibiotics and public education campaign which results in a significant decrease in antibiotic use $[41,44]$; on the other hand, South Korea followed another national policy in the form of banning doctors who dispense drugs that result in significantly reduced the use of generic antibiotics and improved the quality of antibiotic prescriptions, especially for viral infections [45]

The misuse of antibiotics by health-care practitioners and patients can be targeted by developing prescription guidelines, informing the public more thoroughly, regulating the use of antibiotics more strictly, investing more resources in developing new antibiotics, urging physicians to continue going through medical education programs, and promoting the use of alternatives (vaccination, general hygiene, and healthy lifestyles). Vaccination reduces the need, and thus the use, of antibiotics by preventing or reducing infections. General hygiene plays an important role in preventing the dissemination of resistant bacteria. Moreover, healthy diet and exercise enhances physical strength and immunity, and thus reduces the need for antibiotics.

\section{CONCLUSION}

The majority of the sample had a fair level of knowledge in relation to antibiotics. Unfortunately, many people were using antibiotics for the wrong reasons and in the wrong way. Design of national antibiotic awareness campaigns to raise the public awareness towards antibiotic misuse/abuse. More restriction should be applied regarding antibiotic usage as an over-the-counter drugs.

\section{LIMITATION}

- We did a written questionnaire-based survey instead face to face questionnaire.

- Girl locations were unreachable due to the organization and religious reasons; we got help from girl students to carry on this survey.

- Finally, we should consider that not all answers were given honestly due to respondent bias.

\section{ACKNOWLEDGMENT}

we acknowledge all students agreed to participate in the present work as well as all boy and girl students who help us in distribution and collection of the questionnaire.

\section{AUTHORS' CONTRIBUTIONS}

Conception, designing of the study, data collection, data analysis, and interpretation, drafting the article, critical revision of the article, final approval of the study to be published are carried out by Dr. Gomaa. Data collection in the form of questionnaire distribution and collection with done by a number of boy and girl students.

\section{CONFLICTS OF INTEREST}

The author declares that there are no conflicts of interest.

\section{REFERENCES}

1. Grigoryan L, Burgerhof JG, Degener JE, Deschepper R, Lundborg CS, Monnet DL, et al. Determinants of self-medication with antibiotics in Europe: The impact of beliefs, country wealth and the healthcare system. J Antimicrob Chemother 2008;61:1172-9.

2. World Health Organization. The Role of the Pharmacist in Self-Care and Self-Medication: Report of the $4^{\text {th }}$ WHO Consultative Group on the Role of the Pharmacist, The Hague. The Netherlands: WHO; 1998.

3. Roque F, Soares S, Breitenfeld L, López-Durán A, ueiras A,
Herdeiro MT. Attitudes of community pharmacists to antibiotic dispensing and microbial resistance: A qualitative study in Portugal. Int J Clin Pharm 2013;35:417-24.

4. Amabile-Cuevas C. Antibiotic resistance in Mexico: A brief overview of the current status and its causes. J Infect Dev Countries 2010;4:126-31.

5. Zapata-Cachafeiro $\mathrm{M}, \quad$ González-González $\mathrm{C}$, VáquezLago JM, López-Vázquez $\mathrm{P}$, López-Durán A, Smyth E, et al. Determinants of antibiotic dispensing without a medical prescription: A cross-sectional study in the north of Spain. J Antimicrob Chemother 2014;69:3156-60.

6. Plachouras D, Kavatha D, Antoniadou A, Giannitsioti E, Poulakou G, Kanellakopoulou K, et al. Dispensing of antibiotics without prescription in Greece, 2008: Another link in the antibiotic resistance chain. Euro Surveill 2010;15:19488

7. Santa-Ana-Tellez Y, Mantel-Teeuwisse AK, Dreser A, Leufkens HG, Wirtz VJ. Impact of over-the-counter restrictions on antibiotic consumption in Brazil and Mexico. PLoS One 2013;8:e75550.

8. Sabry NA, Farid SF, Dawoud DM. Antibiotic dispensing in Egyptian community pharmacies: An observational study. Res Soc Admin Pharm 2014;10:168-84

9. Al-Faham Z, Habboub G, Takriti F. The sale of antibiotics without prescription in pharmacies in Damascus, Syria. J Infect Dev Countries 2011;5:396-9.

10. Abuiremileh A, Samara S, Alkhodari A, Bahnassi A, Talhouni A, Hayallah M. Antibiotic dispensing of antibiotics without prescription in Jordanian community pharmacies: A pharmacist perspective. Bull Pharm Sci 2014;37:51-63.

11. Al-Mohamadi A, Badr A, Mahfouz LB, Samargandi D, Al Ahdal A. Dispensing medications without prescription at Saudi community pharmacy: Extent and perception. Saudi Pharm J 2013;21:13-8.

12. Abdulhak AA, Al Tannir MA, Almansor MA, Almohaya MS, Onazi AS, Marei MA, et al. Non prescribed sale of antibiotics in Riyadh, Saudi Arabia: A cross sectional study. BMC Public Health 2011;11:1.

13. Salsgiver E, Bernstein D, Simon MS, Eiras DP, Greendyke W, Kubin CJ, et al. Knowledge, attitudes, and practices regarding antimicrobial use and stewardship among prescribers at acute-care hospitals. Infect Control Hosp Epidemiol 2018;39:316-22.

14. Choudhury P, Zulawati A, Munirah L, Ong K, Shahnaz B. Effectiveness of pharmacists' intervention in improving patients knowledge and attitude towards antibiotic usage in klinik kesihatan Seremban, Malaysia. Int J Adv Life Sci Res 2018;1:53-66.

15. Ghosh A, Das S, Dasgupta R. Knowledge, attitude and practices about antimicrobial resistance and appropriate use of antimicrobial agents among the MBBS students of a medical college hospital in Eastern India. Int J Basic Clin Pharmacol 2018;7:370-4.

16. Pan H, Cui B, Zhang D, Farrar J, Law F, Ba-Thein W. Prior knowledge, older age, and higher allowance are risk factors for self-medication with antibiotics among university students in southern China. PLoS One 2012;7:e41314.

17. Aditya S, Rattan A. Self-medication among dental undergraduate students with antibiotics: Looking beyond the known. Asian J Pharm Clin Res 2013;6:132-5.

18. Buke C, Hosgor-Limoncu M, Ermertcan S, Ciceklioglu M, Tuncel M, Köse $\mathrm{T}$, et al. Irrational use of antibiotics among university students. J Infect 2005;51:135-9.

19. Awad AI, Eltayeb IB. Self-medication practices with antibiotics and antimalarials among Sudanese undergraduate university students. Ann Pharmacother 2007;41:1249-55.

20. Napolitano F, Izzo MT, Di Giuseppe G, Angelillo IF. Public knowledge, attitudes, and experience regarding the use of antibiotics in Italy. PLoS One 2013;8:e84177.

21. Sarahroodi S, Arzi A, Sawalha A, Ashtarinezhad A. Antibiotics selfmedication among southern iranian university students. Int J Pharmacol 2010;6:48-52.

22. Maragakis LL, Perencevich EN, Cosgrove SE. Clinical and economic burden of antimicrobial resistance. Expert Rev Antiinfect Ther 2008;6:751-63.

23. Jose J, Jimmy B, Saif AlSabahi G, Al Sabei A. A study assessing public knowledge, belief and behavior of antibiotic use in an omani population. Oman Med J 2013;28:324.

24. Saharan V, Pandey M. A study of prevalance of self medication practice among people of Mumbai. Int J Pharm Pharm Sci 2015;7:253-6.

25. Suman RK, Ray IM, Mohanty N, Mukhia RK, Deshmukh Y. Assessment of usage of antibiotic and their pattern of antibiotic sensitivity test among childhood fever. Int J Pharm Pharm Sci 2014;6:296-9.

26. Harakeh S, Almatrafi M, Ungapen H, Hammad R, Olayan F, Hakim R, 
et al. Perceptions of medical students towards antibiotic prescribing for upper respiratory tract infections in Saudi Arabia. BMJ Open Respiratory Res 2015;2:e00078.

27. Shehadeh M, Suaifan G, Darwish RM, Wazaify M, Zaru L, Alja'fari S. Knowledge, attitudes and behavior regarding antibiotics use and misuse among adults in the community of Jordan. A pilot study. Saudi Pharm J 2012;20:125-33.

28. Zhu X, Pan H, Yang Z, Cui B, Zhang D, Ba-Thein W. Self-medication practices with antibiotics among Chinese university students. Public Health 2016;130:78-83.

29. Oh AL, Hassali MA, Al-Haddad MS, Sulaiman SA, Shafie AA, Awaisu A. Public knowledge and attitudes towards antibiotic usage: A cross-sectional study among the general public in the state of Penang, Malaysia. J Infect Dev Countries 2010;5:338-47.

30. Lim KK, Teh CC. A cross sectional study of public knowledge and attitude towards antibiotics in Putrajaya, Malaysia. Southern Med Rev 2012;5:26.

31. McNulty CA, Boyle P, Nichols T, Clappison P, Davey P. Don't wear me out-the public's knowledge of and attitudes to antibiotic use. J Antimicrob Chemother 2007;59:727-38.

32. Rao MM. assessment of public knowledge and attitude regarding antibiotic use in a tertiary care hospital. Assessment 2016;9:118-22.

33. Mouhieddine TH, Olleik Z, Itani MM, Kawtharani S, Nassar H, Hassoun R, et al. Assessing the Lebanese population for their knowledge, attitudes and practices of antibiotic usage. J Infect Public Health 2015;8:20-31.

34. Liu YC, Huang WK, Huang TS, Kunin CM. Inappropriate use of antibiotics and the risk for delayed admission and masked diagnosis of infectious diseases: A lesson from Taiwan. Arch Internal Med 2001;161:2366-70.

35. Carey B, Cryan B. Antibiotic misuse in the community--a contributor to resistance? Irish Med J 2003;96:43-4, 46.

36. Sarkar P, Gould IM. Antimicrobial agents are societal drugs. Drugs 2006;66:893-901.
37. Chen C, Chen YM, Hwang KL, Lin SJ, Yang CC, Tsay RW, et al. Behavior, attitudes and knowledge about antibiotic usage among residents of Changhua, Taiwan. J Microbiol Immunol Infect 2005;38:53-9.

38. Shah SJ, Ahmad H, Rehan RB, Najeeb S, Mumtaz M, Jilani MH, et al. Self-medication with antibiotics among non-medical university students of Karachi: A cross-sectional study. BMC Pharmacol Toxicol 2014;15:74.

39. Altiner A, Brockmann S, Sielk M, Wilm S, Wegscheider K, Abholz HH. Reducing antibiotic prescriptions for acute cough by motivating GPs to change their attitudes to communication and empowering patients: A cluster-randomized intervention study. J Antimicrob Chemother 2007;60:638-44.

40. Kim SS, Moon S, Kim EJ. Public knowledge and attitudes regarding antibiotic use in South Korea. J Korean Acad Nurs 2011;41:742-9.

41. Morgan DJ, Okeke IN, Laxminarayan R, Perencevich EN, Weisenberg S. Non-prescription antimicrobial use worldwide: A systematic review. Lancet Infect Dis 2011;11:692-701.

42. Olayemi O, Olayinka B, Musa A. Evaluation of antibiotic selfmedication pattern amongst undergraduate students of Ahmadu Bello University (Main Campus), Zaria. Res J Appl Sci Eng Technol 2010;2:35-8.

43. Donkor ES, Tetteh-Quarcoo PB, Nartey P, Agyeman IO. Selfmedication practices with antibiotics among tertiary level students in Accra, Ghana: A cross-sectional study. Int J Environ Res Public Health 2012;9:3519-29.

44. Togoobaatar G, Ikeda N, Ali M, Sonomjamts M, Dashdemberel S, Mori R, et al. Survey of non-prescribed use of antibiotics for children in an urban community in Mongolia. Bull World Health Organ 2010;88:930-6.

45. Park S, Soumerai SB, Adams AS, Finkelstein JA, Jang S, Ross-Degnan D. Antibiotic use following a Korean national policy to prohibit medication dispensing by physicians. Health Policy Planning 2005;20:302-9 